\title{
Commentary
}

See article on page 841

\section{Haemochromatosis after the discovery of HFE ("HLA-H")}

In 1996 the gene and mutation responsible for hereditary haemochromatosis (HHC) were identified. ${ }^{1}$ In the short time since then, this discovery has greatly changed our knowledge of HHC and has given us new methods for its diagnosis and strategies for its management, together with the potential for greater insight into normal and abnormal iron metabolism.

HHC is a common disorder of iron metabolism which results in iron accumulation in parenchymal cells of the liver, heart, and certain endocrine organs, with eventual organ damage such as cirrhosis. It affects 1 in 300 people of northern European descent with a carrier rate of about $10 \%$. Without treatment, the disease is often fatal, but if treatment starts before tissue injury occurs, patients have a normal life expectancy. An early diagnosis of affected individuals is therefore crucial.

The gene identified by Feder et al ("HLA-H" but now defined as $\mathrm{HFE}^{2}$ ) lies approximately $5 \mathrm{Mb}$ telomeric to HLA-A and shows similarity with MHC class I genes. A single mutation is associated with HHC in 65 to $100 \%$ of cases. The mutation is a $\mathrm{G}$ to $\mathrm{A}$ transition at nucleotide 845 and results in the substitution of a cysteine with tyrosine at position 282 (Cys282Tyr) and disruption of a disulphide bridge required to stabilise the protein. A second mutation, a $\mathrm{C}$ to $\mathrm{G}$ change causing an histidine to aspartic acid substitution at position 63 (His63Asp), was also identified but its role, if any, in HHC is controversial.

Worwood et al, in this issue (see page 841), report a study of 115 well characterised patients with HHC in the United Kingdom who were tested for HFE mutations. Most of the patients (91\%) were homozygous for the Cys282Tyr mutation, $4 \%$ were heterozygotes, but $5 \%$ did not carry the mutation. The frequency of the second mutation, His63Asp, was not increased in the patients with HHC compared with the control population. These data further confirm that the Cys282Tyr mutation is responsible for the large majority of the HHC cases and are consistent with the studies published from other white populations. ${ }^{1345}$ However, in southern France and in Italy this proportion becomes smaller, accounting for approximately $70 \%$ of the HHC cases and indicating a more heterogenous disease in these areas. ${ }^{67}$ The frequency of carriers in the general population is approximately $10 \%$ in those of northern European descent. ${ }^{135}$ The Cys282Tyr mutation is not present in African, Asian and indigenous Australasian populations, which is consistent with the distribution of HHC throughout the world. ${ }^{8}$ The His63Asp is not more frequent in patients with HHC $^{134-7}$ and it is widely distributed. ${ }^{8}$ Its role in iron metabolism remains unclear.

What, then, is the cause of HHC in those not carrying the Cys282Tyr mutation? One assumes there are other responsible mutations, either in HFE or elsewhere, but one study from Australia showed that all hereditary HLA linked HHC is due to the Cys282Tyr mutation. ${ }^{4}$
Worwood et al describe the clinical characteristics of six patients with HHC without the Cys282Tyr mutation. Four of them had the classic presentation of HHC but did not have a family history; thus the inheritability of the disease has not been proved. The other two patients had clinical presentations consistent with juvenile haemochromatosis. Symptoms arise in such subjects usually around 20 years of age, especially hypogonadotropic hypogonadism and cardiac dysfunction, and mortality is also unusually high. ${ }^{9}$ Worwood et al showed that patient 2 had a positive family history. Thus, this seems to be a different form of haemochromatosis which does not result from the Cys282Tyr mutation.

As stated by Worwood et al other mutations in HFE or another gene may be the cause of the iron accumulation in patient 2. However, no details on the microsatellites are given and no details on the family members, especially the only other affected member of the family, the older brother who died more than 20 years previously of heart failure. Thus chromosome 6 linked inheritance is still not demonstrated.

Recently, Carella et al presented evidence for a second cause of HHC linked to the HLA-A locus: 16 of 75 (21\%) Italian patients with HHC did not have the Cys282Tyr mutation. Six of these were from family studies and the disease segregated with identical chromosome 6 haplotypes. Carella et al looked for other mutations in HFE in 18 patients who did not carry two copies of the Cys282Tyr mutation and did not find any. They concluded that other mutations may occur in an unexplored region of HFE (introns or the promoter region) or alternatively a mutation may be present in a gene linked to the HLA locus on chromosome 6. Evidence against this hypothesis is that no other common haplotype has been found on the Cys282Tyr negative chromosomes. ${ }^{7}$ If another mutation in HFE or in another gene located in the same genomic region were present, a common haplotype would follow the mutation as a result of lack of recombination in this genomic area. Thus, we currently do not have a clear indication of another cause of HHC linked to HFE on the short arm of chromosome 6 .

As Worwood et al point out, a test based on the Cys282Tyr mutation can be used to confirm the diagnosis in patients with raised iron stores and to screen families. This is likely to lead to a commercially available DNA based test in the near future. A DNA based test will allow the diagnosis of haemochromatosis to be made rapidly but will not provide information about the degree of increased body iron stores or organ damage, the most important prognostic factors. ${ }^{10}$ There is currently no evidence that the haemochromatosis gene mutation is harmful in any other way than through accumulation of excess body iron stores and consequent organ damage. For these reasons and because of the problem of genetic discrimination, serum transferrin saturation, ferritin concentration and liver biopsy are likely to remain the important diagnostic 
tests in the future and the use of the DNA test for screening the general population remains controversial.

S GOLDWURM LW POWELL

Clinical Sciences Unit, The Queensland Institute of Medical Research, Brisbane, Australia 4029

1 Feder JN, Gnirke A, Thomas W, Tsuchihashi Z, Ruddy DA, Basava A, et al. A novel MHC class 1-Iike gene is mutated in patients with hereditary haemochromatosis. Nat Genet 1996; 13: 399-408.

2 Bodmer JG, Parham P, Albert ED, Marsh SGE. Putting a hold on "HLA-H". Nat Genet 1997; 15: 234-5.

3 Beutler E, Gelbart T, West C, Lee P, Adams M, Blackstone R, et al. Mutation analysis in hereditary hemochromatosis. Blood Cells Mol Dis 1996; 22: $187-94$
4 Jazwinska EC, Cullen LM, Busfield F, Pyper WR, Webb SI, Powell LW, et al. Haemchromatosis and HLA-H. Nat Genet 1996; 14: 249-51

5 Jouanolle AM, Gandon G, Jezequel P, Blayau M, Campion ML, Yaouanq J, et al. Haemochromatosis and HLA-H. Nat Genet 1996; 14: 251-2.

6 Borot N, Roth MP, Malfroy L, Demangel C, Vinel JP, Pascal JP, et al. Mutations in the MHC class I like candidate gene for hemochromatosis in French patients. Immunogenetics 1997; 45: 320-4

7 Carella M, D'Ambrosio L, Totaro A, Grifa A, Valentino MA, Piperno A, et al. Mutation analysis of the HLA-H gene in Italian hemochromatosis patients. Am f Hum Genet 1997; 60: 828-32.

8 Merryweather-Clarke AT, Pointon JJ, Shearman JD, Robson KJ. Global prevalence of putative haemochromatosis mutations. $\mathcal{F}$ Med Genet 1997; 34: 275-8.

9 Perkins KW, McInnes IW, Blackbum CR, Beal RW. Idiopathic haemochromatosis in children. Report of a family. Am f Med 1965; 39: 118-26.

10 Niederau C, Fischer R, Sommemberg A, Stremmel W, Trampisch HJ, Strommeyer G. Survival and causes of death in cirrhotic and non-cirrhotic Strommeyer $\mathrm{G}$. Survival and causes of death in cirrhotic and non-cirrhotic 1256-62. 